\title{
Utility of screening chest radiographs in patients with asymptomatic and mildly symptomatic COVID-19 at a field hospital in Samut Sakhon, Thailand
}

Pilawan Trimankha, M.D.

Lakkana Jirapong, M.D.

Runnaya Rungsin, M.D.

Orawan Autravisittikul, M.D.

Pariyanoot Deesuwan, M.D.

Yasinee Mekavuthikul, M.D.

Anocha Chodpanich, M.D.

From Department of Diagnostic Radiology, Samut Sakhon Hospital, Samut Sakhon, Thailand

Address correspondence to P.T. (e-mail: kaewradio@gmail.com)

Received 11 February 2021; revised 4 June 2021; accepted 4 June 2021

doi:10.46475/aseanjr.v22i2.119

\section{Abstract}

Background: In a new episode of the COVID-19 pandemic in Thailand during the beginning of 2021, cases in Samut Sakhon Province mainly occurred in foreign workers and were mostly asymptomatic or had mild disease. To prevent overwhelming the local hospital, a field hospital was established which used chest radiography as one of screening tools for triaging patients.

Objective: To determine the clinical utility of chest radiographs as a screening tool for COVID-19 patients who were asymptomatic or mildly symptomatic. 
Materials and Methods: Six hundred nineteen patients with COVID-19 (confirmed by reverse transcriptase-polymerase chain reaction) were registered at the field hospital at Samut Sakhon provincial sport stadium during 5-8 January 2021 and had chest radiographs taken. The image readings were based on the consensus of two radiologists and a final decision was made by a third radiologist if the first two did not agree. Findings on chest radiographs and clinical outcomes were evaluated.

Results: The study included 619 radiographs; 328/619 (53\%) men and 291/619 (47\%) women had a mean age of 33.3+/- 9.7 (range, 5-64) years. There was mild disease in 13/619, and asymptomatic infections in 606/619. Chest radiographs were normal in $568(91.7 \%)$ and abnormal in 51 (8.3\%) patients; typical findings of COVID-19 were seen in $3(0.5 \%)$ patients. Other abnormal findings were found in $23(3.8 \%)$ patients such as active tuberculosis in $6(1.0 \%)$. Four patients were transferred to the hospital, one of whom required supplemental oxygen.

Conclusion: Combined chest radiographic and clinical information allows better decisions regarding hospital transfers of asymptomatic and mildly symptomatic COVID-19 patients at a field hospital.

Keywords: COVID-19, Chest radiographs, Field hospital. 


\section{Introduction}

The coronavirus disease 2019 (COVID - 19) caused by the novel severe acute respiratory syndrome coronavirus-2 (SARS-COV-2) emerged in Wuhan, China, in December 2019 [1]. It was declared a global pandemic by the World Health Organization (WHO) at 10:00 AM (Central European Time) on 10 February 2021, with 106,321,987 confirmed cases, including 2,325,282 deaths [2]. About $81 \%$ of persons with COVID- 19 have a mild clinical course, while about $14 \%$ have severe and 5\% critical clinical courses [3]. Importantly, 40-45\% of asymptomatic cases can transmit virus for longer than 14 days [4]. The incubation period lasts approximately $4-5$ days, generally within 14 days of exposure $[5,6]$. The standard method to make a definite diagnosis of SAR-COV-2 infection is the reverse transcription-polymerase chain reaction assay (RT-PCR) [7].

Radiological imaging plays a crucial role in the evaluation of disease severity during the course of COVID-19, leading to proper management [8]. Chest X-ray is generally considered to lack sensitivity in identifying pulmonary abnormalities during the early stage of disease [9]. The sensitivity of chest radiography increases from $55 \%$ at less than 2 days, to $79 \%$ at more than 11 days after symptom onset [10]. The Fleischner Society recently released a consensus statement with imaging recommendations for three COVID-19 scenarios; for asymptomatic and mild disease without risk of disease progression, imaging is not recommended [11]. Similarly, the American College of Radiology recommends consideration of use of chest radiography in ambulatory settings only when medically necessary [12].

On 17 December 2020, there was a new patient from a seafood cannery in Samut Sakhon Province, Thailand, infected with COVID-19. There followed a new episode of the pandemic in which the number of infected people increased exponentially, especially among foreign workers. Most infected people were asymptomatic or had mild disease. To prevent overwhelming the local hospital, suspected patients were triaged to a field hospital set up at the Samut Sakhon provincial sport stadium. The triage strategy included medical assessment and 
screening chest radiographs. This study aimed to evaluate the utility of chest radiographs in COVID-19 patients with asymptomatic and mild disease in the field hospital.

\section{Materials and methods}

This retrospective study was approved by the institutional review board of Samut Sakhon Provincial Hospital and written consent from subjects was waived.

\section{Subjects}

The study included 620 patients registered at the field hospital in Samut Sakhon provincial sport stadium during 5-8 January 2021. All patients were moved from the seafood cannery where the initial COVID-19 RT-PCR testing was done using nasopharyngeal swabs 29-31 December 2020. The admission criteria for the field hospital included: COVID-19 infection confirmed by RT-PCR; none or mild symptoms; no limitation in ordinary daily physical activity; no co-morbidity that required in-hospital care.

\section{Definitions}

'Asymptomatic infection' referred to a person with COVID-19 who did not develop symptoms [13].

'Mild disease' referred to a person who had any of the various signs and symptoms of COVID-19 (e.g., fever, cough, fatigue, anorexia, myalgia, sore throat, nasal congestion, headache, gastrointestinal symptom, loss of smell or taste) and was without evidence of hypoxia [14].

\section{Field hospital workflow}

The workflow began with passport identification and registration of each patient. Then the medical staff asked whether the patient met the criteria for admission. Chest radiographs were taken 1-2 days after admission (about one week after positive COVID-19 RT-PCR). The field hospital had: self-monitoring stations for 
vital parameters including temperature, oxygen saturation and blood pressure; 24-hour camera monitoring; telecommunication when required. Foreign patients were divided into small groups, each of which was observed by a representative or volunteer who had good ability to communicate with the medical and support staff. If there was a high risk of clinical deterioration, based on abnormal follow-up chest radiographs or developing symptoms, the volunteer placed a yellow flag at the patient's bed to allow for closer monitoring.

Patients were discharged if no symptoms developed during 10 days of observation in the field hospital.

\section{Chest radiographic process and image analysis}

All patients admitted to the field hospital had chest radiographs except one (without an identified cause), resulting in 619 initial radiographs. All chest radiographs were digital, in the postero-anterior projection, and obtained using a mobile X-ray machine (Quest HF series, Quantum Medical Imaging) in a bus. The final reports of chest radiographs were based on readings by two radiologists ( 4 and 7 years post-board certification). If there was any discordance, the final decision would be made by a third radiologist (19 years post-board certification).

Chest radiograph reports were classified as 'normal' if there was no abnormality and as 'abnormal' if there was any abnormality. Abnormal chest radiographic findings were categorized as i) typical of COVID-19 pneumonia, ii) indeterminate, or iii) other findings.

'Typical' findings of COVID-19 pneumonia were defined as bilateral multi-focal round opacities with lower lobe predominance [15].

'Indeterminate' findings of COVID-19 pneumonia were defined as unilateral, central or upper lung opacities [15].

'Other' findings were defined as findings which raised alternative diagnoses such as tuberculosis (active or non-active), bronchiectasis, lung fibrosis [15]. 
To simplify for clinical management, radiologists decided to have suggestions in each abnormal report categorized as i) medical attention was required, ii) follow-up chest radiograph was recommended, or iii) no further management was needed. Final decision for transfer of patients to the hospital was determined by the managing clinical team, based on evidence of clinical deterioration and abnormal chest radiography.

\section{Measure of primary outcome}

- Patient transferred to regular hospital or remained in field hospital.

\section{Data collection and statistic analysis}

Demographic variables including age, sex, and ethnicity were collected at the time of registration at the field hospital. Symptoms, co-morbidities, body weight, height, medical treatment and clinical outcome were collected and recorded in the electronic hospital information system of Samut Sakhon Hospital.

Demographic variables were statistically analyzed and described as mean, dispersion and proportion. Chest radiograph reports were also analyzed as proportions. Correlations between chest radiograph report, symptoms, co-morbidities and clinical outcome were analyzed using Pearson Chi-square and Fisher's exact tests.

\section{Results}

\section{Clinical characteristics of COVID-19 patients (Table 1)}

In patients who had chest radiographs $(\mathrm{n}=619)$, there were $328(53 \%)$ men and 291(47\%) women. The average age was $33.3+/-9.7$ (ranging between 5 and 64) years old. There were three national origins: 616 from Myanmar (99.5\%), two Thai $(0.3 \%)$, and one Cambodian $(0.2 \%)$. There were only 13 patients with symptoms and these were mild; the most common presenting symptom was cough (7/13). There were 30 patients with co-morbidities; the most common was hypertension $(13 / 30)$. 
Table 1. Clinical characteristic for COVID-19 patients.

\begin{tabular}{|c|c|}
\hline Parameter & Number/Total (\%) \\
\hline $\begin{array}{l}\text { Sex } \\
\text { Male } \\
\text { Female }\end{array}$ & $\begin{array}{l}328 / 619(53 \%) \\
291 / 619(47 \%)\end{array}$ \\
\hline $\begin{array}{l}\text { Age } \\
<15 \text { years } \\
15-59 \text { years } \\
>60 \text { years } \\
\text { Mean age years } \pm S D \\
(\text { Min-max) }\end{array}$ & $\begin{array}{c}5 / 619(0.8 \%) \\
612 / 619(98.9 \%) \\
2 / 619(0.3 \%) \\
33.3 \pm 9.7 \\
(5-64 \text { years })\end{array}$ \\
\hline $\begin{array}{l}\text { Ethnicity } \\
\text { Myanmar } \\
\text { Thai } \\
\text { Cambodia }\end{array}$ & $\begin{array}{c}616 / 619(99.5 \%) \\
2 / 619(0.3 \%) \\
1 / 619(0.2 \%)\end{array}$ \\
\hline $\begin{array}{l}\text { Body mass index }(\mathrm{BMI}, \mathrm{kg} / \mathrm{m} 2) \\
<18.5 \\
18.5-22.9 \\
>23.0 \\
\text { Mean } \pm \text { SD } \\
\text { (Min-max) } \\
\text { No data }\end{array}$ & $\begin{array}{c}21 / 619(3.4 \%) \\
109 / 619(17.6 \%) \\
144 / 619(23.3 \%) \\
23.94 \pm 4.4 \\
(15.67-43.28) \\
345 / 619(55.7 \%)\end{array}$ \\
\hline $\begin{array}{l}\text { Symptoms } \\
\text { Cough } \\
\text { Sore throat } \\
\text { Chest discomfort } \\
\text { Headache } \\
\text { Dyspnea }\end{array}$ & $\begin{array}{l}7 / 619(1.1 \%) \\
3 / 619(0.5 \%) \\
3 / 619(0.5 \%) \\
1 / 619(0.2 \%) \\
1 / 619(0.2 \%)\end{array}$ \\
\hline $\begin{array}{l}\text { Co -morbidities } \\
\text { Hypertension } \\
\text { Old tuberculosis (TB) } \\
\text { Diabetes } \\
\text { Cerebrovascular disease } \\
\text { Allergy }\end{array}$ & $\begin{array}{l}13 / 619(2.1 \%) \\
8 / 619(1.3 \%) \\
6 / 619(1.0 \%) \\
3 / 619(0.5 \%) \\
1 / 619(0.2 \%) \\
\end{array}$ \\
\hline
\end{tabular}




\section{Chest radiographic findings (Table 2)}

Normal chest radiographs accounted for 91.7\% (568/619), whereas the other 8.3\% (51/619) were abnormal. Abnormal chest radiographs were typical of COVID-19 in $0.5 \%(3 / 619)$, indeterminate in $4 \%(25 / 619)$ and had other findings in $3.8 \%$ (23/619). Active tuberculosis was found in $26.2 \%(6 / 23)$ of those with 'other' findings.

Table 2. Chest radiograph findings in COVID-19 patients.

\begin{tabular}{|lc}
\hline Chest radiographic findings & Number/Total (\%) \\
\hline Normal & $568 / 619(91.7 \%)$ \\
\hline Abnormal & $51 / 619(8.3 \%)$ \\
- Typical COVID -19 pattern & $3 / 619(0.5 \%)$ \\
- Indeterminate & $25 / 619(4 \%)$ \\
- Other findings & $23 / 619(3.8 \%)$ \\
- Old TB & $7 / 23(30.5 \%)$ \\
- Active TB & $6 / 23(26.2 \%)$ \\
- Lung nodules & $2 / 23(8.7 \%)$ \\
- Lung fibrosis & $2 / 23(8.7 \%)$ \\
- Cardiomegaly & $2 / 23(8.7 \%)$ \\
- Bronchiectasis & $1 / 23(4.3 \%)$ \\
- Calcified lymph nodes & $1 / 23(4.3 \%)$ \\
- Enlarged hilar nodes & $1 / 23(4.3 \%)$ \\
- Situs inversus & $1 / 23(4.3 \%)$ \\
Total & $619 / 619(100 \%)$ \\
\hline
\end{tabular}

\section{Chest radiographic findings related to having asymptomatic or mild disease} (Table 3)

Of the asymptomatic patients, there were abnormal chest radiographs in $8.3 \%$ (50/606) with typical findings of COVID-19 pneumonia in $0.5 \%(3 / 606)$, intermediate in $4 \%(24 / 606)$, and other findings in 3.8\% (23/606). Of the 13 patients with mild disease, chest radiographs were normal in 12 and indeterminate in one. There were no significant differences between the abnormal chest radiographic findings of asymptomatic and mildly symptomatic patients. 
Table 3. Chest radiograph findings for COVID-19 patients as related to having asymptomatic or mild disease.

\begin{tabular}{lccccc}
\hline & Asymptomatic & Mild disease & Total & P-value & 95\% CI \\
\hline Normal CXR, & $556 / 606$ & $12 / 13$ & $568 / 619$ & 0.88 & $88.5-93.1 \%$ \\
number/total (\%) & $(91.7 \%)$ & $(92.3 \%)$ & $(91.7 \%)$ & & \\
\hline Abnormal CXR, & $50 / 606$ & $1 / 13$ & $51 / 619$ & 0.68 & $6.9-11.5 \%$ \\
number/total (\%) & $(8.3 \%)$ & $(7.7 \%)$ & $(8.3 \%)$ & & \\
Typical pattern, & $3 / 606$ & $0 / 13$ & $3 / 619$ & 0.81 & \\
number/total (\%) & $(0.5 \%)$ & $(0 \%)$ & $(0.5 \%)$ & & \\
Indeterminate, & $24 / 606$ & $1 / 13$ & $25 / 619$ & 0.27 & \\
number/total (\%) & $(4 \%)$ & $(7.7 \%)$ & $(4 \%)$ & & \\
Other findings, & $23 / 606$ & $0 / 13$ & $23 / 619$ & 0.39 & \\
number/total (\%) & $(3.8 \%)$ & $(0 \%)$ & $(3.8 \%)$ & & \\
\hline
\end{tabular}

\section{Correlations between outcomes and co-morbidities, symptoms, chest radiographs (Table 4)}

A correlation between co-morbidities, symptoms, chest radiographs and the necessity to transfer a patient to the hospital was found to be statistically significant $(p<0.05)$ only for abnormal chest radiographs. No mortality occurred.

Table 4. Correlations between outcomes and co-morbidities, symptoms, chest radiographs.

\begin{tabular}{lccccc} 
& Total & $\begin{array}{c}\text { Remain in } \\
\text { field hospital }\end{array}$ & $\begin{array}{c}\text { Transferred } \\
\text { to hospital }\end{array}$ & Mortality & P-value \\
\hline $\begin{array}{l}\text { Comorbidities } \\
\text {-Yes }\end{array}$ & 30 & 29 & 1 & 0 & 0.18 \\
$\quad$ - No & 589 & 586 & 3 & & \\
$\begin{array}{l}\text { Symptoms } \\
\quad \text { - Asymptomatic }\end{array}$ & 606 & 602 & 4 & 0 & 1.00 \\
- Mild disease & 13 & 13 & 0 & & \\
$\begin{array}{l}\text { Chest report } \\
\text { - Normal }\end{array}$ & 568 & 566 & 2 & 0 & 0.036 \\
- Abnormal & 51 & 49 & 2 & & \\
\hline
\end{tabular}




\section{Follow-up of transferred patients}

There were four patients transferred to the hospital. Two of them were transferred due to typical radiographic findings of COVID-19 and were given favipiravir due to their abnormal chest radiographs (Figure 1). One of them had a history of old pulmonary TB. Both patients had no symptoms during admission and no need of oxygen treatment. After complete treatment, there was resolution of pulmonary opacities on the chest $\mathrm{x}$-rays.

One patient who was asymptomatic and had a normal chest radiograph on the first day of admission, developed sudden acute dyspnea in the second day and was transferred to the hospital. The follow-up chest radiograph after transfer to the hospital showed unilateral patchy ground glass opacity (Figure 1). This patient was given favipiravir and oxygen therapy due to acute dyspnea. Finally, this patient was found to be immunocompromised based on a low CD-4 count.

The fourth patient was transferred to the hospital due to acute psychosis from drug withdrawal and was not given favipiravir since there was no indication.
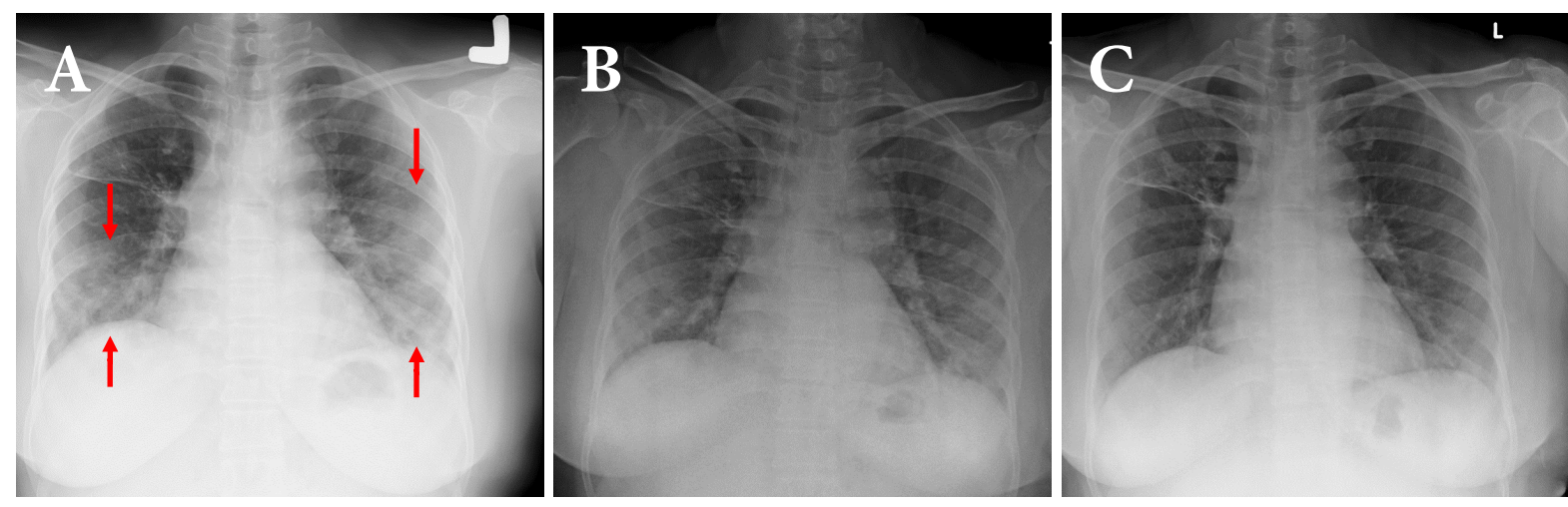

Figure 1. Chest radiographs with typical pattern of COVID-19 pneumonia. Patient was asymptomatic and had previous pulmonary tuberculous infection. (A) The first chest radiograph taken at the field hospital revealed multifocal bilateral opacities in mid to lower lung zones. Fibrosis in right upper lobe was also noted. (B) The follow-up chest radiograph, 5 days after the first one and on the day after completion of favipiravir treatment, revealed partial resolution of the pulmonary opacities. (C) The chest radiograph before discharge reveals resolution of pulmonary opacities. 

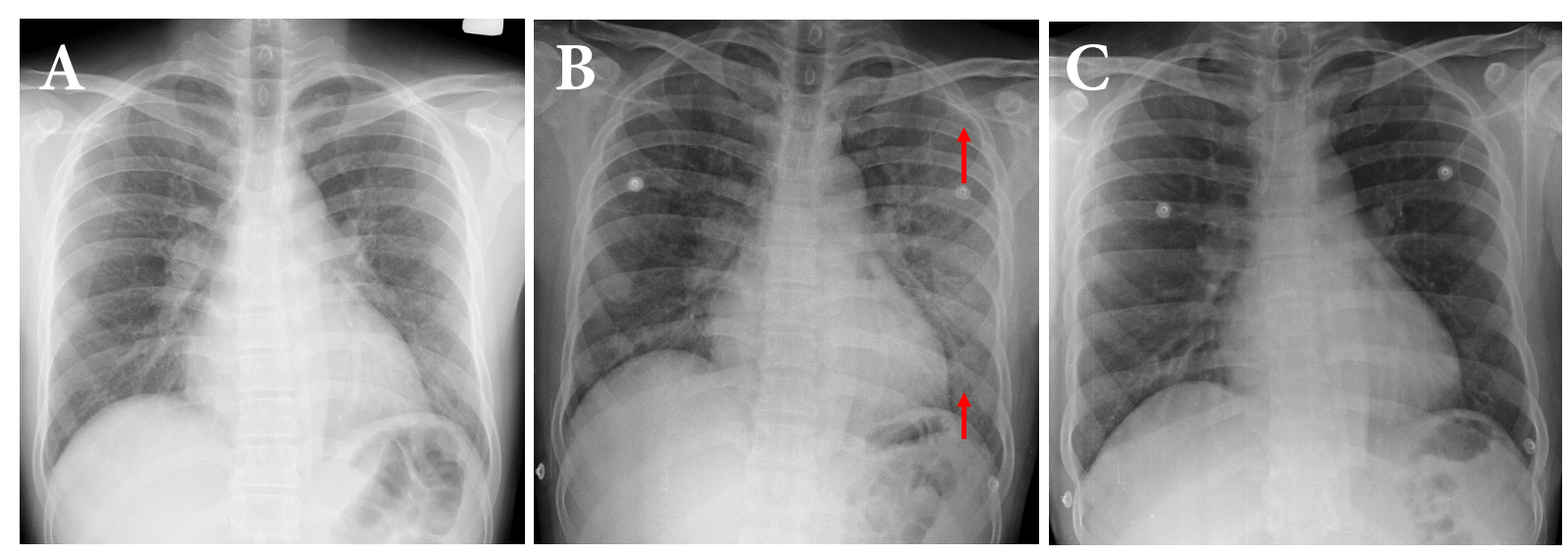

Figure 2. Radiographs of a 37-year-old male who developed acute dyspnea and was transferred to the hospital. (A) The initial chest radiograph reveals no pulmonary infiltration. (B) The follow-up chest radiograph, which was taken after he had dyspnea and oxygen saturation of $94 \%$, reveals unilateral patchy ground glass opacities in mid to lower left lung zones. (C) Chest radiograph 4 days after starting favipiravir treatment reveals resolution of the pulmonary opacities.

\section{Discussion}

The ongoing COVID-19 pandemic caused a large burden to national health systems. A good triage system was needed to prioritize patients and prevent overwhelming hospitals. For asymptomatic and mild COVID-19-infected cases, the Fleischer Society recommends that chest radiography is not indicated unless there is a risk of clinical deterioration [11]. In moderate to severe COVID-19, there is no doubt that chest radiographs help monitor disease progression and predict outcomes $[16,17]$.

In this study, the 619 chest $\mathrm{x}$-rays of asymptomatic and mild COVID-19 patients revealed normal findings in $91.7 \%$. This result was consistent with other reports that most asymptomatic and mildly symptomatic patients have normal chest radiographs. Kuo, et al. [18] reported that screening chest radiographs in asymptomatic and mild disease in Singapore were normal in $98.0 \%(1,925 / 1,964)$ and showed findings of pulmonary infection in $2.0 \%$. 
Of the abnormal chest radiographs, there were chest findings typical of COVID-19 in $0.5 \%(3 / 619)$, indeterminate in $4 \%(25 / 619)$ and other findings in $3.8 \%(23 / 619)$. In the 'other' findings, active tuberculosis was diagnosed in 1\% (6/619). Of the 4 patients who were transferred to the hospital, abnormal chest radiograph was the only parameter which was significantly correlated $(\mathrm{P}<0.05)$. This was likely due to the agreement of clinical management team that abnormal chest radiographs reflected a high risk of disease progression.

Two patients transferred because of typical chest radiographic findings of COVID-19 pneumonia were asymptomatic during the whole length of hospital stay. They were treated with favipiravir and their follow-up chest radiographs showed complete resolution (Figure 1). One patient with typical chest radiographic findings of COVID-19 pneumonia remained in the field hospital and was discharged after a 10-day asymptomatic course. Initially, the chest radiograph of the last patient was reported as showing indeterminate findings and the clinical management team decided not to transfer the patient to the hospital. However, retrospective review led to a consensus among radiologists that the $\mathrm{x}$-ray findings were typical of a COVID-19 pattern.

The 'typical' COVID-19 pattern should be differentiated from that of other infections, organizing pneumonias or results from lung insults due to etiologies such as medications and recreational drugs [14]. Yet the typical chest radiographic findings in asymptomatic patients might not be a definite indication for transfer of patients to the hospital and might not predict the course of disease. Parry, et al. [19] reported that asymptomatic infection could have a variable clinicalradiological course, spanning resolution, progression and no change. However, in the progression group, patients also had high levels of C-reactive protein and L-delactohydrogenase, as well as lower lymphocyte counts. This implied that other factors are needed to properly triage asymptomatic patients beyond chest radiographs.

One transferred patient was initially asymptomatic with a normal chest radiograph. However, the day after admission he developed sudden dyspnea requiring in-hospital supplemental oxygen and his follow-up chest radiograph 
demonstrated abnormal lung opacifications (Figure 2). This could be explained by either an initial false negative chest radiograph or rapid progression of disease. However, there was no comparative computed tomography which is known to be superior to chest radiograph in demonstrating early findings [20].

The fourth patient was transferred to hospital because of acute psychosis due to drug withdrawal. It should be kept in mind that etiologies non-related COVID-19 continue to occur in such critical periods. An additional benefit of the chest x-ray screening program was the detection of active pulmonary tuberculosis, which allowed personal isolation and safety of others in the field hospital.

There were some limitations in this study. First, there were indeterminate findings in nearly $50 \%$ of the abnormal chest radiographs which could not be resolved with computed tomography. They might be due to subtle disease, overlying breast tissue, or other processes. Second, the small number of transferred patients limited the power of the statistical analysis. Third, the lack of available data about the date of symptom onset in each patient impaired the calculation of sensitivity of chest radiography. Finally, the outcomes of discharged patients were not tracked and so late complications were not detected.

\section{Conclusion}

Combined chest radiograph and clinical information make better decision for transferred-in hospital in asymptomatic and mild symptomatic COVID-19 patients at filed hospital.

Acknowledgment: The authors would like to thank radiologists, technicians and the supporting team of the Samut Sakhon Hospital, and clinical management team of the field hospital at Samut Sakhon provincial sport stadium. The authors also thank Mrs. Nattawan Sangurai for statistic analysis.

Declaration of competing interests: The authors declare that they have no competing financial interests nor personal relationships that could have appeared to influence the work reported in this paper. 


\section{References}

1. Huang C, Wang Y, Li X, Ren L, Zhao J, Hu Y, et al. Clinical features of patients infected with 2019 novel coronavirus in Wuhan, China. Lancet 2020;395:497506. doi: 10.1016/S0140-6736(20)30183-5.

2. World Health Organization [Internet].Geneva: The Organization; 2021 [cited 2021 Jul 1]. Coronavirus Disease 2019 (COVID-19) Dashboard; [about 7 screens]. Available from: https:// www. Covidi2.who.int

3. $\mathrm{Wu} \mathrm{Z}$, Mcgoogan GM. Characteristics of and important lessons from the Coronavirus Disease 2019 (COVID-19) outbreak in China: summary of a report of 72314 cases from the Chinese Center for Disease Control and Prevention. JAMA 2020;323:1239-42. doi: 10.1001/jama.2020.2648.

4. Oran DP, Topol EJ. Prevalence of asymptomatic SARS-CoV-2 infection. Ann InternMed 2020;173:362-7. doi: 10.7326/M20-3012.

5. Li Q, Guan X, Wu P, Wang X, Zhou L, Tong Y, et al. Early transmission dynamics in Wuhan, China, of Novel Coronavirus-I-infected pneumonia. N Engl J Med 2020;382:1199-207. doi: 10.1056/NEJMoa2001316.

6. Guan WJ, Ni ZY, Hu Y, Liang WH, Ou CQ, He JX, et al. Clinical characteristics of Coronavirus Disease 2019 in China. N Engl J Med 2020;382:1708-20. doi: 10.1056/NEJMoa2002032.

7. Chinese Society of Radiology, Chinese Medical Association. Radiological diagnosis of New Corona Virus infected pneumonitis: expert recommendation from Chinese Society of Radiology (First Edition). Chin J Radiol [Internet] 2020 [cited 2021 Jul 1];4:279-85. Chinese. Available from: http://rs.yiigle.com/ CN112149202004/1187937.htm 
8. Zu ZY, Jiang MD, Xu PP, Chen W, Ni QQ, Lu GM, et al. Coronavirus Disease 2019 (COVID-19): a perspective from China. Radiology 2020;296:E15-25. doi: 10.1148/radiol.2020200490.

9. Ng MY, Lee EYP, Yang J, Yang F, Li X, Wang H, et al. Imaging profile of the COVID-19 infection: radiologic findings and literature review. Radiol Cardiothorac Imaging 2020;2:e200034. doi: 10.1148/ryct.2020200034.

10. Stephanie S, Shum ST, Cleveland H, Challa SR, Herring A, Jacobson FL,et al. Determinants of chest X-Ray sensitivity for COVID-19: a multi-institutional study in the United States. Radiol Cardiothorac Imaging 2020;2: e200337. doi: $10.1148 /$ ryct.2020200337

11. Rubin GD, Ryerson CJ, Haramati LB, Sverzellati N, Kanne JP, Raoof S, et al. The role of chest imaging in patient management during the COVID-19 pandemic: a multinational consensus statement from the Fleischner Society. Radiology 2020;296:172-80. doi: 10.1148/radiol.2020201365.

12. ACR American College of Radiology [Internet]. Reston(VA): ACR; 2020 Mar 11 [updated 2020 Mar 22; cited 2021 Jul 1]. ACR recommendations for the use of chest radiography and Computed Tomography (CT) for suspected COVID-19 infection. Available from: https://www.acr.org/Advocacyand-Economics/ACR-Position-Statements/Recommendations-for-ChestRadiography-and-CT-for-Suspected-COVID19-Infection.

13. World Health Organization [Internet]. Geneva: WHO; 2020 Apr 2 [cited 2021 Jul 1]. Coronavirus Disease 2019 (COVID-19) situation report -73. Available from: https://www.who.int/docs/default-source/coronaviruse/ situation-reports/20200402-sitrep-73-covid-19.pdf?sfvrsn=5ae25bc7_6.

14. World Health Organization [Internet]. Geneva: WHO; 2020 [cited 2021 Jul 1].Use of chest imaging in COVID-19: a rapid advice guide 11 June 2020. Available from: https://apps.who.int/iris/handle/10665/332336 
15. Litmanovich DE, Chung M, Kirkbride RR,, Kicska G, Kanne JP. Review of chest radiograph findings of COVID-19 pneumonia and suggested reporting language. J Thorac Imaging 2020;35:354-60. doi: 10.1097/RTI. 0000000000000541 .

16. Borghesi A, Maroldi R. COVID-19 outbreak in Italy: experimental chest X-ray scoring system for quantifying and monitoring disease progression. Radiol Med 2020;125:509-13. doi: 10.1007/s11547-020-01200-3.

17. Hui TCH, Khoo HW, Young BE, Haja Mohideen SM, Lee YS, Lim CJ, et al. Clinical utility of chest radiography for severe COVID-19. Quant Imaging Med Surg 2020;10:1540-50. doi: 10.21037/qims-20-642.

18. Kuo BJ, Lai YK, Tan MLM, Goh XC. Utility of screening chest radiographs in patients with asymptomatic or minimally symptomatic COVID-19 in Singapore. Radiology 2021;298:E131-40. doi: 10.1148/radiol.2020203496.

19. Parry AH, Wani AH, Yaseen M, Shah NN, Dar KA. Clinicoradiological course in coronavirus disease-19 (COVID-19) patients who are asymptomatic at admission. BJR Open 2020;2:20200033.doi: 10.1259/bjro.20200033.

20. Wong HYF, Lam HYS, Fong AH, Leung ST, Chin TW, Lo CSY, et al. Frequency and distribution of chest radiographic findings in patients positive for COVID-19. Radiology. 2020;296:E72-8. doi: 10.1148/radiol.2020201160. 